\title{
ESTUDO DA REMOÇÃO DE ÍONS FERRO E MANGANÊS DA ÁGUA UTILIZANDO PERÓXIDO DE HIDROGÊNIO COMO AGENTE OXIDANTE
}

\section{EVALUATION OF REMOVAL OF IRON AND WATER MANGANESIDES USING HYDROGEN PEROXIDE AS OXIDIZING AGENT}

\author{
M. F. APOLINÁRIO ${ }^{1}$, L. M. MEIRELES ${ }^{1}$, D. J. SILVA*1 e H. F. SANTANA² \\ ${ }^{1}$ Universidade Federal de Viçosa, Departamento de Química, Viçosa, Minas Gerais, Brasil \\ ${ }^{2}$ Serviço Autônomo de Água e Esgoto, Viçosa, Minas Gerais, Brasil
}

${ }^{*}$ Corresponding author. Federal University of Viçosa, Department of Chemical, Viçosa, Minas Gerais, Brazil,

e-mail addressl: deusanilde@ufv.br (D. J. Silva).

\begin{tabular}{|c|}
\hline ART I CLE INFO \\
\hline $\begin{array}{l}\text { Article history: } \\
\text { Received 2018-07-12 } \\
\text { Accepted 2018-09-28 } \\
\text { Available online 2018-10-31 }\end{array}$ \\
\hline $\begin{array}{l}\text { palavras-chave } \\
\text { Agente Oxidante } \\
\text { Tratamento de água } \\
\text { Peróxido de hidrogênio } \\
\text { Água de abastecimento urbanc }\end{array}$ \\
\hline $\begin{array}{l}\text { keywords} \\
\text { Oxidizing Agent } \\
\text { Water treatment } \\
\text { Hydrogen peroxide } \\
\text { Water supply }\end{array}$ \\
\hline
\end{tabular}

\begin{abstract}
A B S T R A C T
The inadequate disposal of effluents in lakes and rivers, associated with the increase of dissolved organic matter, has been pointed out as one of the main causes of the increment in the concentration of iron and manganese ions present in the water. In this work, the use of hydrogen peroxide as an oxidizing agent at near neutral $\mathrm{pH}$ was studied in an attempt to remove ions in the form of the precipitates. Tests were carried out on jar tests at different concentrations of the oxidant, ranging from 0.63 to $3.8 \mathrm{ppm}$, associated to a dosage of 20 ppm aluminium polychloride "PAC", coagulant usually used in Water Treatment Stations. Under these conditions, was consumed $90 \%$ of iron and $36 \%$ of manganese despite of the consume of peroxide was until $40 \%$. It wasn't observed significant effect to different dosages of the peroxide.
\end{abstract}

R E S U M O

\begin{abstract}
O despejo inadequado de efluentes em lagos e rios, associado ao incremento da matéria orgânica dissolvida, tem sido apontado como uma das principais causas do aumento da concentração de íons ferro e manganês presentes na água. Neste trabalho, estudou-se o uso de peróxido de hidrogênio como agente oxidante, em $\mathrm{pH}$ próximo ao neutro, na tentativa de remover os íons na forma de precipitados. Foram realizados ensaios em testes de jarros em diferentes concentrações do oxidante, entre valores de 0,63 a $3,8 \mathrm{ppm}$, associado a uma dosagem de 20 ppm de policloreto de alumínio "PAC", coagulante usualmente utilizados em Estações de Tratamento de Água. Nestas condições, observou-se a remoção de $90 \%$ de íons ferro e $36 \%$ de íons manganês, sendo que o consumo de peroxido foi de até $40 \%$. Não foi observado efeito significativo sobre os resultados para as diferentes dosagens de oxidante.
\end{abstract}




\section{INTRODUÇ̃̃̃O}

A água é uma das substâncias fundamentais para a existência da vida na terra. Embora cerca de $70 \%$ da superfície terrestre seja coberta por água, apenas cerca de $3 \%$ é própria para o consumo humano e de animais (VON SPERLING, 2005). Entretanto, para ser inserida dentro dos limites de potabilidade a fim de se evitar qualquer tipo de contaminação e transmissão de doenças, é necessário que a mesma seja submetida a um conjunto de procedimentos químicos e físicos nas Estações de Tratamento de Água (ETAs) (DI BERNARDO, 2005).

De acordo com a portaria $\mathrm{n}^{\mathrm{o}} 2.914$ de 12 de dezembro de 2011 do Ministério da Saúde, para que a água seja considerada potável, ela deve atender a alguns requisitos após tratamento, tais como: turbidez menor que $0,5 \mathrm{uT}$, cor até $15 \mathrm{uH}$, concentração dos íons ferro menor que $0,3 \mathrm{mg} \mathrm{L}^{-1}$, concentração de íons manganês menor que $0,1 \mathrm{mg} \mathrm{L}^{-1}$, ausência de coliformes totais e Escherichia coli em $100 \mathrm{~mL}$ de amostra e concentração de cloro residual de 0,2 a $2 \mathrm{mg} \mathrm{L}^{-1}$ em toda extensão do sistema de distribuição (BRASIL, 2011).

A elevada demanda hídrica causada pelo aumento populacional nos centros urbanos e industriais, associada à preservação e manutenção insatisfatórias dos mananciais, diminui gradativamente a qualidade da água captada para tratamento. Além disso, a presença de dejetos industriais e esgoto e o baixo índice pluviométrico das chuvas pode elevar a concentração de compostos tóxicos e de matéria orgânica dissolvida, exigindo esforços cada vez maiores para atingir o padrão de potabilidade da água de abastecimento exigido pela portaria (VON SPERLING, 2005).

Dentre os problemas que ocorrem com elevada frequência, o aumento da concentração de íons ferro e manganês na água tem se destacado. Segundo Moruzzi \& Reali 2012, o ferro e o manganês na forma $\mathrm{Fe}^{2+}$ e de $\mathrm{Mn}^{2+}$ formam compostos solúveis, mas ao entrarem em contato com ambiente oxidante, se precipitam na forma de $\mathrm{Fe}^{3+}$ ou $\mathrm{Mn}^{4+}$ dando origem a compostos insolúveis que conferem à água a coloração avermelhada para os precipitados de ferro e marrom escuro para os precipitados de manganês, além de deixá-la com um aspecto turvo.

Segundo relatório da Organização Mundial da Saúde (2011), apesar das concentrações usualmente encontradas não conferirem risco a saúde humana, a presença de ferro e manganês acima do estabelecido pela portaria $n^{\circ} 2.914$ do Ministério da Saúde em águas de abastecimento podem promover alguns inconvenientes, como: alteração de odor e sabor da água; aparecimento de manchas em louças, roupas e vasos sanitários; aparecimento de incrustações e de bactérias ferruginosas no sistema de distribuição e interferência em processos industriais. Além disso, de acordo com Moruzzi \& Reali (2012), a presença desses metais pode comprometer a confiabilidade da população abastecida no sistema de tratamento público, devido à presença de coloração e turbidez.

Em vista disso, alguns métodos já foram estabelecidos para propiciar o controle da remoção desses íons dissolvidos em água. Segundo Di Bernardo (2005), os mais utilizados em sistemas de saneamento ambiental são oxidação em $\mathrm{pH}$ apropriado com aeração ou com outro agente oxidante, tais como cloro, permanganato de potássio, dióxido de cloro ou ozônio, seguido da filtração para remoção dos precipitados formados. Entretanto, como citado por Mattos et. al. (2003), os processos mais eficientes no tratamento de efluente são os Processos Oxidativos Avançados, comumente denominados por POA, que se baseiam na geração do radical hidroxila $\left(\mathrm{OH}^{\bullet}\right)$ para promover a degradação de vários compostos poluentes em pouco tempo, por ser um radical com alto poder oxidante. Ainda segundo o mesmo autor, essa prática já é comum em países desenvolvidos há, aproximadamente, 25 anos que utiliza o peróxido de hidrogênio associado ao ozônio para a geração do radical no tratamento de água e de esgoto.

Neste trabalho propõe-se a utilização do peróxido de hidrogênio como agente oxidante da água bruta, com o objetivo de reduzir íons ferro e manganês da água tratada, em substituição à utilização de agentes halogenados, evitando assim a formação de compostos cancerígenos (trialometanos).

\section{MATERIAIS E MÉTODOS}

A realização deste trabalho foi subdividida em quatro etapas: (a) coleta e caracterização da água bruta; (b) determinação do equivalente de oxidação (OXE) entre o hipoclorito de cálcio, reagente utilizado pelo SAAE como agente oxidante, e o peróxido de hidrogênio $50 \mathrm{~V}$ utilizado nos testes; (c) ensaios de bancadas de Teste em Jarros para avaliação da remoção dos íons dissolvidos, e (d) análise estatística (ANOVA). Ressalta-se que os ensaios foram realizados nos laboratórios da Estação de Tratamento de Água I do SAAE, Viçosa-MG.

\subsection{Coleta e caracterização da água bruta}

No dia 15 de maio de 2018, foram coletados cerca de 60 L de água do manancial de abastecimento da cidade de Viçosa MG, Rio Turvo, com o auxílio de quatro bombonas de $20 \mathrm{~L}$ cada, previamente lavadas. Desta água, foram amostradas 50 $\mathrm{mL}$ para a realização da caracterização da água bruta: cor, turbidez e pH. Para a determinação destes parâmetros utilizouse metodologias baseadas em espectrofotometria (para análises de cor aparente, turbidez e concentração de íons) e potenciometria (para as análises de $\mathrm{pH}$ e condutividade) em equipamentos da marca Policontrol.

Uma segunda amostra foi reservada para análise de absorção atômica com o objetivo de quantificação dos íons ferro e manganês dissolvidos. O restante da água foi armazenada sob refrigeração em geladeira, a $4{ }^{\circ} \mathrm{C}$, durante os sete dias de análises para a realização deste trabalho. Ressalta-se ainda que para cada novo dia de análises, amostras da água acondicionada eram retiradas para verificação dos parâmetros físico-químicos.

Uma dosagem inicial de íons $\mathrm{Mn}^{2+}$ foi adicionada à água na forma de sulfato de manganês $\left(\mathrm{MnSO}_{4}\right)$ de forma que a concentração do íon manganês fosse elevada o suficiente para proceder-se à avaliação. Neste trabalho, a água coletada no Rio Turvo com a adição de sulfato de manganês foi considerada a água bruta para efeito dos testes. 
2.2. Determinação do equivalente de oxidação entre hipoclorito de cálcio e peróxido de hidrogênio

Para a dosagem da água bruta com hipoclorito de cálcio, foi inicialmente preparada $1 \mathrm{~L}$ de solução de hipoclorito de cálcio 0,00065 M, pesando-se 0,14 gramas do reagente e transferindo-se o conteúdo quantitativamente para um balão volumétrico de $1.000 \mathrm{~mL}$, diluído em água destilada até completar o volume. Uma bureta de $25 \mathrm{~mL}$ foi completada com essa solução para realizar a dosagem do mesmo.

Posteriormente, $100 \mathrm{~mL}$ de água bruta foram transferidos para um Erlenmeyer de $250 \mathrm{~mL}$ e dosado com $0,5 \mathrm{~mL}$ de hipoclorito. O conteúdo foi mantido por 1 minuto sob agitação constante, quando parte foi retirada para reação com o reagente DPD, com posterior leitura espectrofotométrica Aquacolor cloro marca AquaControl, para medir o cloro livre. Após leitura, ambos os conteúdos foram descartados, tanto o restante no Erlenmeyer quanto o presente na cubeta de leitura do aparelho AquaColor cloro, para dar início a uma nova leitura. O Erlenmeyer, assim como a cubeta, foram lavados com água destilada, evitando-se qualquer contato com a água de torneira.

Esse procedimento foi feito repetidamente para várias dosagens de hipoclorito, até que se obteve vários pontos necessários para a construção de uma curva do poder de oxidação. Os testes foram realizados em duplicata.

\subsubsection{Cálculo do equivalente oxidativo}

Nas reações de oxirredução do hipoclorito de cálcio, cada átomo de cloro com número de oxidação +1 é capaz de aceitar 2 elétrons para ser reduzido ao estado de oxidação termodinamicamente mais estável -1 , formando o ânion $\mathrm{Cl}^{-}$ (MORAIS, 2005). Essa reação de oxirredução pode ser observada na Equação 1:

$\mathrm{Ca}(\mathrm{OCl})_{2}+4 \mathrm{e}^{-}+2 \mathrm{H}_{2} \mathrm{O} \rightarrow 2 \mathrm{Cl}^{-}+\mathrm{Ca}^{2+}+4 \mathrm{OH}^{-}$

Para as moléculas de peróxido de hidrogênio, a equação de oxirredução pode ser escrita conforme a Equação 2 (MATTOS, et al. 2003):

$$
\mathrm{H}_{2} \mathrm{O}_{2}+2 \mathrm{H}^{+}+2 \mathrm{e}^{-} \rightarrow 2 \mathrm{H}_{2} \mathrm{O}
$$

De acordo com as equações 1 e $2,1 \mathrm{~mol}$ de $\mathrm{Ca}(\mathrm{OCl})_{2}$ equivale a $2 \mathrm{~mol}$ de $\mathrm{H}_{2} \mathrm{O}_{2}$ para que haja a transferência da mesma quantidade de elétrons. Assim, levando-se em consideração a massa molar do hipoclorito de cálcio $\left(142,98 \mathrm{~g} \mathrm{~mol}^{-1}\right)$ e a do peróxido de hidrogênio (34 $\left.\mathrm{g} \mathrm{mol}^{-1}\right)$, a relação entre esses compostos é mostrada na Equação 3.

$\mathrm{X}=2 * 34 / 142,98=0,476 \mathrm{Kg}$

Dessa forma, $1 \mathrm{Kg}$ de hipoclorito de cálcio equivale a 476 $\mathrm{g}$ de peróxido de hidrogênio, para fins de tratamento de água. Aplicando-se essa relação, tem-se que uma dosagem de 4,05 ppm de hipoclorito de cálcio equivalem a uma dosagem de 1,92 ppm de peróxido de hidrogênio, que será tomado como base nos testes em jarros.

\subsection{Ensaios de bancada}

\subsubsection{Determinação da concentração ideal de Policloreto de Alumínio (PAC) por teste em jarros}

Cada um dos seis jarros foi lavado e completado com 2 litros de água bruta. Os respectivos tubos de ensaios foram preenchidos com um determinado volume da solução de PAC de forma que os jarros possuíssem a concentrações de $0,10,15$, 20, 25 e 30 ppm de PAC durante os ensaios. O equipamento foi ajustado de acordo com a programação apresentada na Tabela 1.

Tabela 1. Programação utilizada no teste de jarros, para determinação da concentração ideal de PAC

\begin{tabular}{ccc} 
Etapa & Rotação /rpm & Tempo /min \\
\hline $\begin{array}{l}\text { Adição de } \\
\text { coagulante }\end{array}$ & 50 & 1 \\
$\begin{array}{l}\text { Mistura do } \\
\text { coagulante }\end{array}$ & 100 & 1 \\
Floculação & 50 & 30 \\
Decantação & 0 & 5 \\
\hline
\end{tabular}

Decorrido esse tempo, uma amostra de aproximadamente $100 \mathrm{~mL}$ de cada jarro foi coletada, tomando-se o cuidado de descartar os primeiros $100 \mathrm{~mL}$ para eliminação do volume morto contido nas mangueiras de drenagem da água dos jarros.

Cada uma das amostras passou por uma leitura de cor, turbidez e acidez através dos aparelhos de colorímetro, turbidímetro e pHmetro disponíveis na ETA. O ensaio jar test foi realizado em duplicata. A dosagem de PAC que apresentou o menor valor de turbidez da água final, foi a adotada em testes posteriores.

\subsubsection{Efeito do peróxido de hidrogênio na qualidade da água}

Foi realizado um ensaio de teste de jarros para avaliar o efeito conjunto da adição de peróxido de hidrogênio e do PAC na oxidação e subsequente remoção de íons ferro e manganês dissolvidos na água.

Para esta nova etapa das análises, procedeu-se a utilização dos jarros, como na etapa anterior, sendo que o equipamento foi ajustado de acordo com a programação apresentada na Tabela 2 . O tempo de residência de 1 min para o peróxido de hidrogênio foi considerado para se aproximar das condições reais da ETA. 
Tabela 2. Programação utilizada no teste de jarros, para avaliar o efeito do peróxido de hidrogênio como agente préoxidante

\begin{tabular}{ccc}
\hline Etapa & Rotação /rpm & Tempo /min \\
\hline $\begin{array}{c}\text { Adição do } \\
\text { peróxido }\end{array}$ & 50 & 1 \\
$\begin{array}{c}\text { Mistura do } \\
\text { peróxido }\end{array}$ & 100 & 1 \\
$\begin{array}{c}\text { Adição de } \\
\text { coagulante }\end{array}$ & 50 & 1 \\
$\begin{array}{c}\text { Mistura do } \\
\text { coagulante }\end{array}$ & 100 & 1 \\
Floculação & 50 & 30 \\
Decantação & 0 & 5
\end{tabular}

Para a distribuição das dosagens de PAC e peróxido de hidrogênio nos jarros, seguiu-se as dosagens apresentadas na Tabela 3.

Tabela 3. Distribuição das dosagens do coagulante e oxidante no teste de jarros

\begin{tabular}{ccc}
\hline Jarros & $\begin{array}{c}\text { Dosagem de PAC } \\
\text { /ppm }\end{array}$ & $\begin{array}{c}\text { Dosagem de } \\
\text { peroxido de } \\
\text { hidrogênio /ppm }\end{array}$ \\
\hline 1 & 20 & 0,00 \\
2 & 20 & 0,63 \\
3 & 20 & 1,26 \\
4 & 20 & 1,90 \\
5 & 20 & 2,53 \\
6 & 20 & 3,80 \\
\hline
\end{tabular}

Ao final do tempo de teste, uma amostra de, aproximadamente, $100 \mathrm{~mL}$ de cada jarro foi coletada concomitantemente, tomando-se o cuidado de descartar os primeiros $100 \mathrm{~mL}$ para eliminação do volume morto contido nas mangueiras de drenagem da água dos jarros.

Parte desse volume foi utilizada para leitura de $\mathrm{pH}$, turbidez e cor. Uma segunda parte foi retirada para leitura de peróxido de hidrogênio residual por meio das fitas de leitura de peróxido de hidrogênio da marca Merck KGaA. O restante foi enviado para o laboratório de absorção atômica para leitura do ferro e manganês remanescente.

\subsection{Análise estatística}

A análise da eficiência de remoção dos íons ferro e manganês dissolvidos na água utilizando-se peróxido de hidrogênio como agente oxidante foi feita pelo método de análise de variância (ANOVA).

\section{RESULTADOS E DISCUSSÃO}

\subsection{Caracterização da água bruta}

$\mathrm{Na}$ Tabela 4 são apresentados os resultados da caracterização da água bruta.

Tabela 4. Resultados dos parâmetros da água bruta e o os permitidos por legislação

\begin{tabular}{ccc}
\hline Parâmetro & $\begin{array}{c}\text { Obtidos neste } \\
\text { trabalho }\end{array}$ & Legislação* $^{*}$ \\
\hline $\mathrm{pH}$ & 6,9 & $6,0-9,5$ \\
Cor, $\mu \mathrm{C}$ & 71,4 & 15,0 \\
Turbidez, NTU & 13,3 & 0,5 \\
[Fe], ppm & 0,9 & 0,3 \\
{$[\mathrm{Mn}], \mathrm{ppm}$} & $0,1 \rightarrow 1,6$ & 0,1 \\
\hline
\end{tabular}

*Valores máximos permitidos, para água potável de acordo com a portaria n 2.914 de 12 de dezembro de 2011 do Ministério da Saúde.

De acordo com a portaria $\mathrm{n}^{\circ} 2.914$ de 12 de dezembro de 2011 do Ministério da Saúde, para que a água seja considerada potável, a concentração dos íons ferro deve ser menor que 0,3 ppm e a concentração de íons manganês menor que 0,1 ppm. Assim, para melhor observação dos efeitos dos procedimentos propostos, optou-se por adicionar sulfato de manganês à água bruta para elevar a concentração deste composto, obtendo-se um valor de 1,649 ppm de íons manganês.

\subsection{Equivalente de oxidante de hipoclorito e peróxido de hidrogênio}

Para prosseguir os experimentos e definir a concentração de peróxido de hidrogênio a ser utilizada que garantisse um potencial oxidante eficiente, realizou-se um teste para a verificação do poder redutor da água bruta coletada. Para isto, utilizou-se o hipoclorito de cálcio como agente oxidante e avaliou-se a concentração de íons cloro livre após a reação. Realizou-se a dosagem de cloro na água bruta até atingir valores próximos a $2 \mathrm{mg} \mathrm{L}^{-1}$, valor máximo permitido pela portaria $\mathrm{n}^{\circ}$ 2.914 de 12 de dezembro de 2011 do Ministério da Saúde.

Realizado o experimento, foi observado que para valores da dosagem de hipoclorito, aproximadamente igual a $5 \mathrm{ppm}$ apresentaram um residual de cloro livre igual a $2 \mathrm{ppm}$ (Figura 1). A partir destes dados fez-se a comparação da quantidade de peróxido de hidrogênio necessária para oxidar a mesma quantidade de matéria, chegando-se ao valor de 1,98 ppm. 


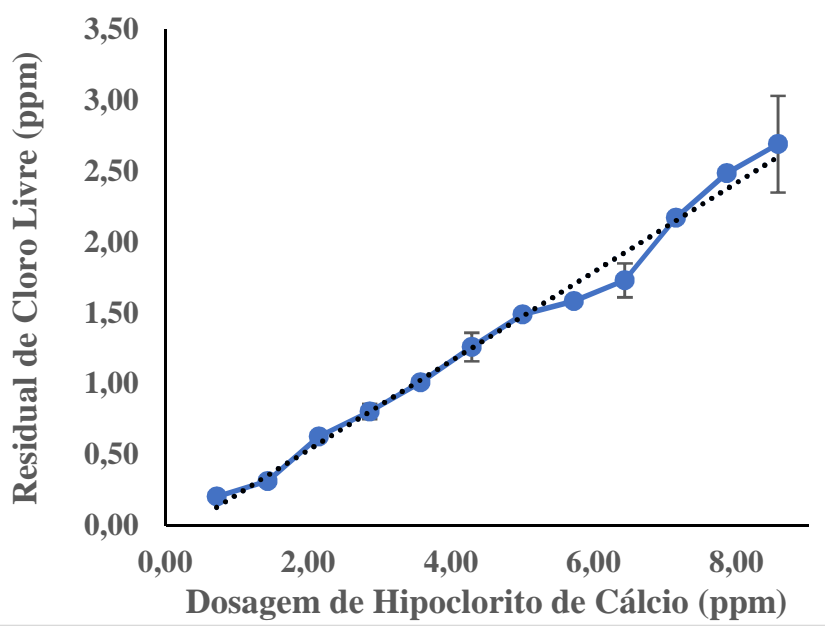

Figura 1. Ensaio com hipoclorito de cálcio para a dosagem do poder oxidativo da água bruta

Verifica-se que a adição de cloro na água-bruta promove o consumo deste composto devido às reações de oxido-redução com a matéria orgânica disponível. Souza \& Daniel (2005), observaram o rápido consumo de cloro livre adicionado à água contendo matéria orgânica em elevada concentração. Estes autores verificaram ainda a diminuição do poder antimicrobiano do cloro, quando a matéria orgânica estava presente, confirmando o favorecimento da ocorrência das reações de óxido-redução nas condições empregadas no estudo.

\subsection{Concentração ideal do PAC}

Realizado o ensaio em teste de jarros para a determinação da concentração ideal de PAC, efetuou-se a análise dos parâmetros físico-químicos (cor, turbidez e $\mathrm{pH}$ ) da água submetida aos diferentes tratamentos, como apresentado nas Figuras 2, 3 e 4, respectivamente.

Verificou-se que na concentração de 20 ppm de PAC, a remoção da cor foi em torno de $88 \%$, chegando a uma cor final de $8 \mu \mathrm{C}$. Dosagens acima de 20 ppm não apresentaram valores de remoção significativamente maiores, sendo que para valores de 25 ppm e 30 ppm foram removidos cerca de 88,64\% e $88,44 \%$, respectivamente, como mostra a Figura 2.

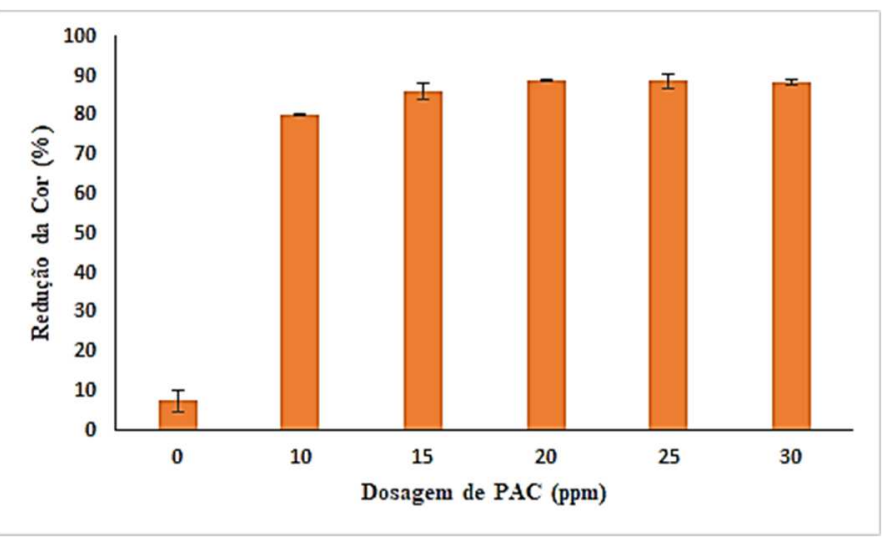

Figura 2. Redução da cor nas amostras de água bruta submetidas ao tratamento com Policloreto de Alumínio
A avaliação dos valores de turbidez das amostras após o tratamento com PAC, demonstrou que para valores superiores a 20 ppm de PAC, não apresentaram uma redução pronunciada do parâmetro avaliado. Na concentração de 20 ppm o valor de turbidez final da amostra foi de 1,42 NTU, o que significa uma redução de aproximadamente $89,32 \%$, como apresentado na Figura 3.

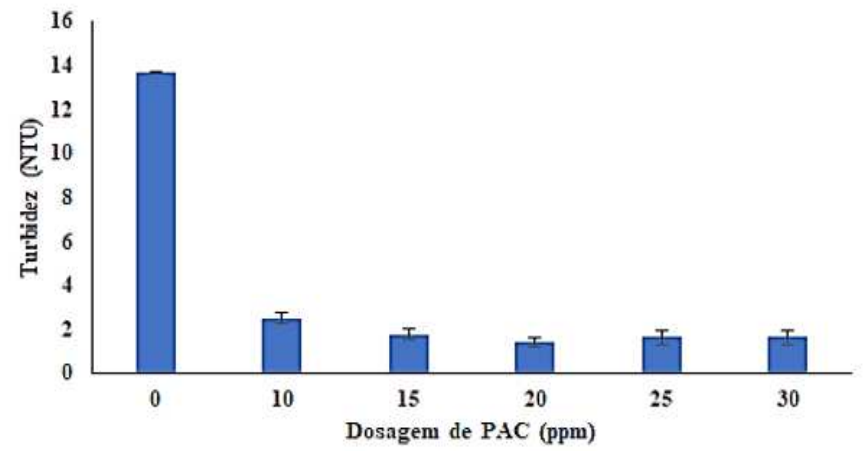

Figura 3. Turbidez das amostras de água bruta submetidas ao tratamento com Policloreto de Alumínio

$\mathrm{O}$ valor de $\mathrm{pH}$ das amostras foi avaliado para todas as condições, sendo observado que neste ensaio manteve-se perto da neutralidade em todas as concentrações de PAC utilizadas no experimento, como apresentado na Figura 4.

Padilha et. al. (2011) ao avaliarem a ação do policloreto de alumínio a 10 ppm, sobre a turbidez da água de abastecimento da cidade de Maringá-PR, verificaram a redução da turbidez da água bruta próximo a 95\%. Veneu et. al. (2015), observaram que na concentração de PAC igual $50 \mathrm{ppm}$ foi eficiente para a diminuição dos valores de turbidez e cor acima de $90 \%$. Observa-se que a composição química da água de abastecimento varia de acordo com o local da captação, sendo necessárias diferentes dosagens do coagulante para o tratamento da água, justificando assim a necessidade de realizar um teste de coagulação para determinação da concentração ótima de coagulante.

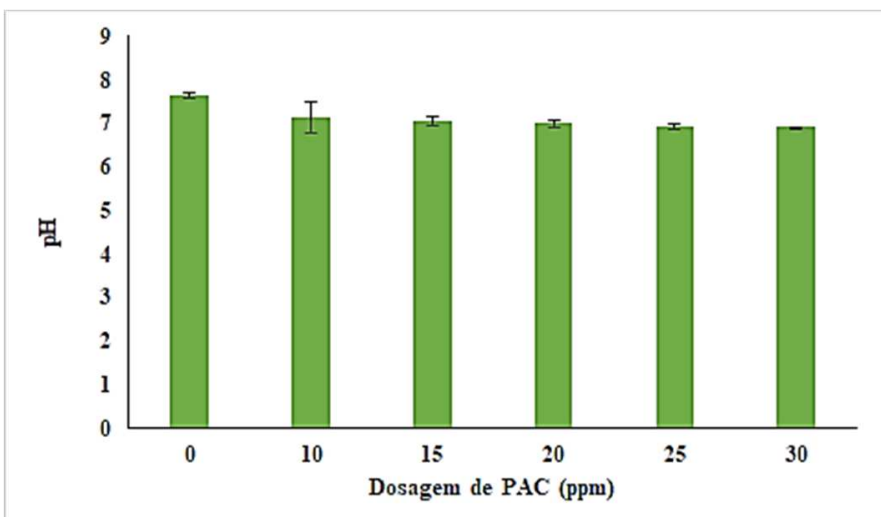

Figura 4. Variação do pH das amostras de água bruta submetidas ao tratamento com Policloreto de Alumínio

Os parâmetros de tratabilidade da água atingidos após a utilização do PAC a 20 ppm foram cor igual a $8 \mu \mathrm{C}$, turbidez igual a 1,42 NTU e pH 6,99. Desta forma, a partir dos dados obtidos experimentalmente fixou-se a concentração de PAC 
para uso nos próximos ensaios, igual a 20 ppm, uma vez que esta concentração apresentou melhor resposta aos parâmetros avaliados.

\subsection{Efeito da oxidação com peróxido de hidrogênio na qualidade da água}

Os resultados médios dos parâmetros físico-químicos, cor, turbidez, pH, concentração de íons ferro e manganês estão apresentado nas Figuras 5, 6, 7, 8 e 9, respectivamente.

De acordo com os resultados, não houve diferença estatística dos testes realizados com o peróxido de hidrogênio e o teste referência, sem peróxido. Os valores médios alcançados para redução da cor e da turbidez se encontraram em torno de $80 \%$, como observado nos Figuras 5 e 6.

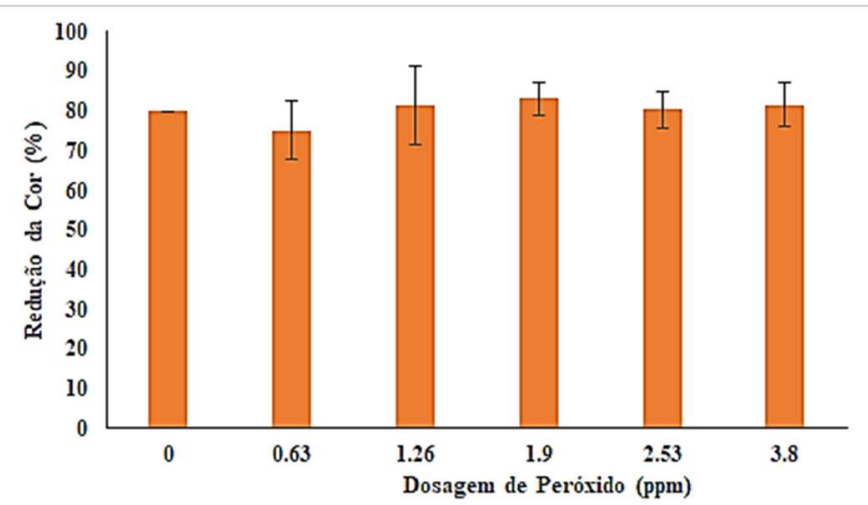

Figura 5. Redução da cor nas amostras de água bruta submetidas ao tratamento com Policloreto de Alumínio (20ppm) e Peróxido de Hidrogênio

Veneu et al. (2015), ao utilizarem o dióxido de cloro, composto de alto poder oxidante, na faixa de concentração de 1 a 3 ppm para tratar água bruta, verificaram a remoção de $90 \%$ da cor para todas as amostras, e $90 \%$ de remoção da turbidez para as amostras tratadas com 1,0 ppm e 1,8 ppm. Valores acima de 2,0 ppm, apresentaram valores menores para a remoção da turbidez, devido à interação entre o oxidante e os microorganismos, que ao serem lizados causariam aumento da turbidez do meio.

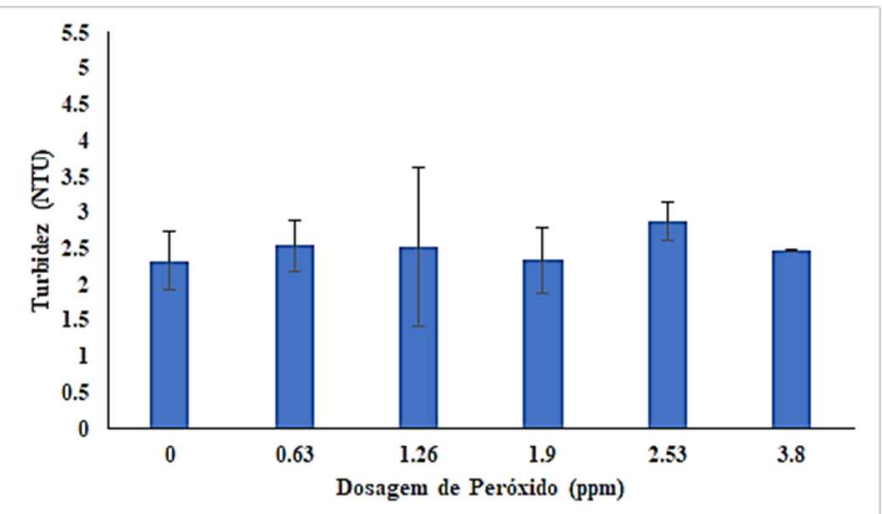

Figura 6. Turbidez das amostras de água bruta submetidas ao tratamento com Policloreto de Alumínio (20ppm) e Peróxido de Hidrogênio
Adicionalmente, entre os valores médios para o $\mathrm{pH}$ dos testes de referência e para aqueles com peróxido de hidrogênio, também não houve diferença estatística (Figura 7), e todos os valores situam-se perto da neutralidade, $\mathrm{pH} 7$.

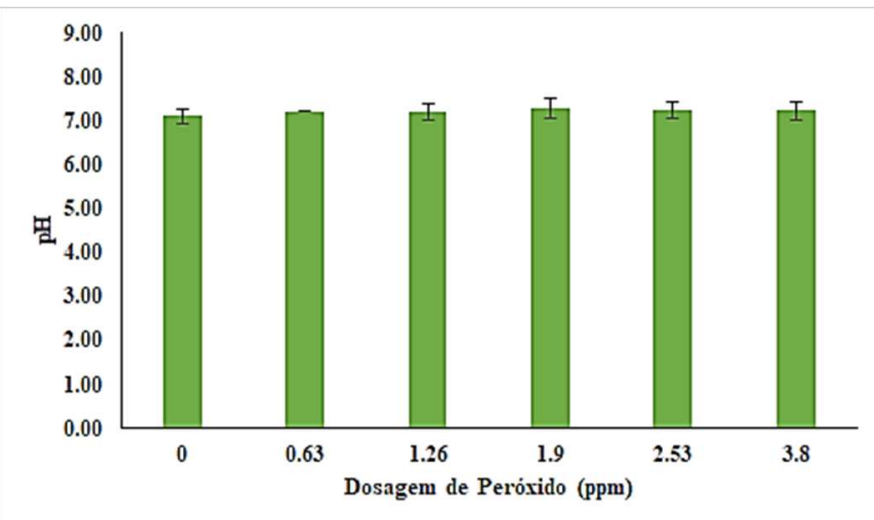

Figura 7. Variação do pH das amostras de água bruta submetidas ao tratamento com Policloreto de Alumínio (20 ppm) e Peróxido de Hidrogênio

Nas Figuras 8 e 9 estão apresentados os resultados médios para a remoção dos teores de $\mathrm{Fe}$ e de $\mathrm{Mn}$, respectivamente, da água bruta com a aplicação do peróxido de hidrogênio como agente pré-oxidante. Por si só, a dosagem do coagulante contribuiu com a remoção de $83,44 \%$ de íons ferro (Figura 8). De acordo com a análise de variância, não houve diferença estatística entre os resultados, embora o teste com 3,8 ppm de peróxido tenha apresentado $90 \%$ de remoção de íons ferro. Igualmente para os resultados de teor de íons manganês, não houve diferença significativa entre os resultados. Os resultados médios para remoção situam-se em torno de $38 \%$ (Figura 9).

Araújo \& Baydum (2017) testaram a remoção de íons manganês e ferro da água bruta do açude de Mossoró-RN, pela utilização do peróxido de hidrogênio e hidróxido de sódio. Foi observado que o uso combinado dos compostos promoveu a remoção completa dos metais avaliados, o que não foi observado quando somente o peróxido de hidrogênio foi testado. Esta análise corrobora para a necessidade de valores de $\mathrm{pH}$ elevados para a ação oxidante do peróxido nas águas de abastecimento.

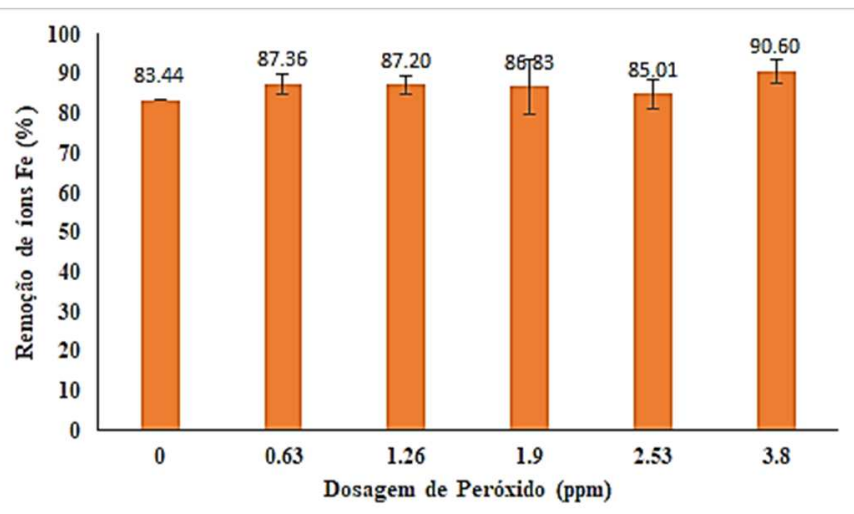

Figura 8. Porcentagem de remoção de íons ferro da água bruta submetida ao tratamento com Policloreto de Alumínio (20 ppm) e Peróxido de Hidrogênio 


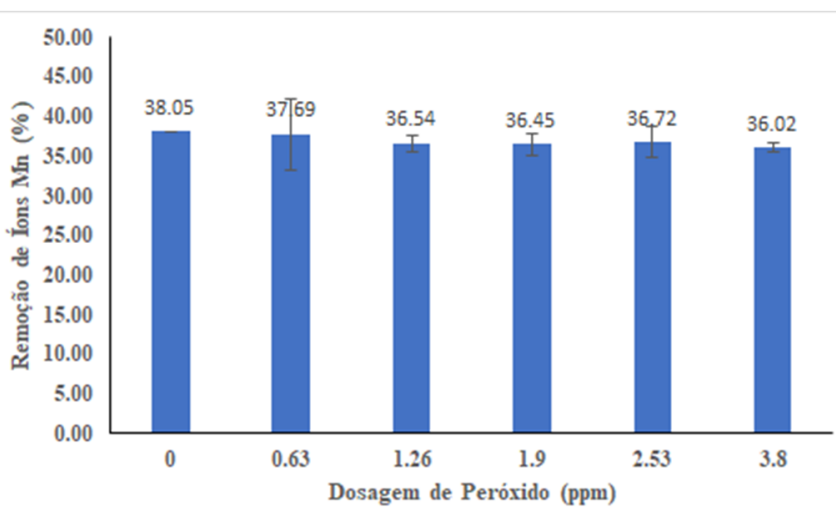

Figura 9. Turbidez das amostras de água bruta submetidas ao tratamento com Policloreto de Alumínio (20ppm) e Peróxido de Hidrogênio

Segundo Di Bernardo \& Dantas (2005), a remoção de íons manganês é favorecida em valores de $\mathrm{pH}$ acima de 8,0, uma vez que nesta faixa começa a ocorrer a formação de óxidohidróxido de manganês (MnO-OH), composto insolúvel e de fácil remoção. Para valores abaixo desta faixa, o manganês encontra-se na forma de íon divalente, dificultando a formação de complexos precipitáveis. Da mesma forma, Moruzzi \& Reali (2012) também verificaram que os íons $\mathrm{Fe}^{2+}$ e $\mathrm{Mn}^{2+}$ precipitam quase que completamente como carbonatos para valores de $\mathrm{pH}$ acima de 8,5, e como hidróxidos para valores de $\mathrm{pH}$ acima de 11.

Os dados obtidos neste trabalham concordam com os dados apresentados por Di Bernardo \& Dantas (2005), Moruzzi $\&$ Reali (2012) e Pires (2013). De acordo com a Figura 7, o valor do $\mathrm{pH}$ das amostras submetidas ao tratamento, apresentaram $\mathrm{pH}$ em valores na faixa da neutralidade, o que dificultaria a precipitação e remoção dos íons, em especial do íon manganês.

Foi ainda verificado o residual de peróxido remanescente na água após tratamento. Observou-se que parte do peróxido adicionado reagiu com a matéria redutora disponível, mantendo ainda um remanescente significativo para todas as dosagens testadas, como apresentado na Tabela 5.

Tabela 5. Concentração do residual de peróxido ao fim do tratamento com Policloreto de Alumínio (20ppm) e Peróxido de Hidrogênio

\begin{tabular}{ccc}
\hline $\begin{array}{c}\text { Dosagem de } \\
\text { PAC /ppm }\end{array}$ & $\begin{array}{c}\text { Dosagem de } \\
\text { peróxido /ppm }\end{array}$ & $\begin{array}{c}\text { Peróxido } \\
\text { consumido/ } \%\end{array}$ \\
\hline 0 & 0,00 & 0,00 \\
20 & 0,00 & 0,00 \\
20 & 0,63 & 20,6 \\
20 & 1,26 & 16,7 \\
20 & 1,90 & 47,4 \\
20 & 2,53 & 17,0 \\
20 & 3,80 & 18,9 \\
\hline
\end{tabular}

Perucci, Rodrigues e Silva (2017) verificaram que ao utilizar o peróxido de hidrogênio como agente pré-oxidante em substituição ao cloro na água bruta para abastecimento, um residual significativo de peróxido era detectado, mesmo por um longo tempo de contato. Ao utilizar uma concentração inicial de 2,00 ppm de peróxido, um residual de 1,70 ppm foi detectado, mesmo para um tempo longo de contato $(20 \mathrm{~h})$. No entanto, pela avaliação do objetivo tratado pelos autores, a utilização de peróxido foi eficiente por diminuir a concentração de trihalometanos formados durante o tratamento. Ressalta-se que nesse trabalho, o pH da água encontrava-se em torno de 5-6, valores estes que podem ter interferido na ação do peróxido.

Todavia, destaca-se que a utilização do peróxido de hidrogênio no presente trabalho, não trouxe alterações negativas ao tratamento e nem à ação do coagulante, mantendo os padrões de cor, turbidez e $\mathrm{pH}$, dentro do esperado.

\section{CONCLUSÕES}

Este trabalho avaliou o efeito da adição de peróxido de hidrogênio, em uma etapa de pré-oxidação, na redução dos íons ferro e manganês da água bruta. Os resultados alcançados permitiram fazer as seguintes conclusões:

1) Nas condições testadas, a inserção da etapa de préoxidação com peróxido de hidrogênio não apresentou ganhos na redução dos parâmetros cor e turbidez e das concentrações dos íons $\mathrm{Fe}^{2+}$ e de $\mathrm{Mn}^{2+}$ da água bruta.

2) A utilização do PAC na etapa de coagulação, por si só, conseguiu reduzir $83,44 \%$ e $38,05 \%$ dos íons ferro e manganês, respectivamente, e de $80 \%$ a turbidez da água bruta;

3) Nas condições avaliadas, a ação do peróxido de hidrogênio foi parcialmente suprimida, apresentando pouca relevância para o tratamento da água.

Diante do exposto, sugere-se o emprego de novos ensaios para avaliação do efeito do $\mathrm{pH}$ sob a ação do peróxido de hidrogênio, a fim de verificar o potencial de precipitação dos íons manganês sob diferentes condições de $\mathrm{pH}$, mesmo que as condições de $\mathrm{pH}$ em operação normal da ETA-SAAE-Viçosa, sejam próximo a 7 .

Ainda, para verificar a eficiência do processo, sugere-se a realização de testes que avaliem a cinética de reação e o tempo de contato necessário para a ação do peróxido de hidrogênio, pois, neste trabalho, o tempo de residência foi somente de $1 \mathrm{~min}$.

\section{AGRADECIMENTOS}

Os autores agradecem ao SAAE-Viçosa pelo convite e apoio dados à pesquisa, e às agências de fomento FAPEMIG, CAPES e CNPq, pelo apoio financeiro.

\section{R E F E R E N C I A S}

ARAÚJO, J. K.; BAYDUM, V. P. A. Estudo do uso combinado de hidróxido de sódio e peróxido de hidrogênio em manancial eutrofizado destinado ao abastecimento humano, In: ABES/AESABESP, XXVII Congresso Interamericano de Engenharia Sanitária e Ambiental, FENASAN 2017. Anais eletrônicos. Disponível em:<http://servicos.compesa.com.br/wpcontent/uploads/2017/11/ESTUDO-DO-USOCOMBINADO-DE-HIDR\%C3\%93XIDO-DE- 
S\%C3\%93DIO-E-PER\%C3\%93XIDO-DEHIDROG\%C3\%8ANIO-EM-MANANCIALEUTROFIZADO-DESTINADO-AOABASTECIMENTO-HUMANO.pdf >. Acesso em 27 de Junho de 2018.

BRASIL. Ministério da Saúde. Portaria No 2914/2011. Dispõe sobre os procedimentos de controle e de vigilância da qualidade da água para consumo humano e seu padrão de potabilidade. Diário Oficial [da] União, 12 dez. 2011. Availableat:http://bvsms.saude.gov.br/bvs/saudelegis/g m/2011/prt2914_12_12_2011.html. Acesso em 20 de Maio de 2018.

DI BERNARDO, L.; DANTAS, A. D.B., Métodos e técnicas de tratamento de água, 2ed. São Carlos, 792p.RiMa, 2005.

MATTOS, I.L., SHIRAISH, K.A., BRAZ A. D., FERNANDES J.B. Peróxido de hidrogênio: importância e determinação. Revista Química Nova. Bauru-SP, v. 26, n. 3, p. 373-380, 2003.

MORAIS, J. L. Estudo da potencialidade de processos oxidativos avançados, isolados e integrados com processos biológicos tradicionais, para tratamento de chorume de aterro sanitário. 2005. 229 f, Tese (Doutorado em Química). Universidade Federal do Paraná. Curitiba- PR. 2005.

MORUZZI, R. B., REALI, M. A. P. Oxidação e remoção de ferro e manganês em águas para fins de abastecimento público ou industrial - uma abordagem geral, Revista de Engenharia e Tecnologia, V. 4, No. 1, Abr/2012.

ORGANIZAÇÃO MUNDIAL DA SAÚDE, Manganese in Drinking-water, Geneva, Switzerland, 2011. Disponível em:http://www.who.int/water_sanitation_health/dwq/ch emicals/manganese.pdf. Acesso em 07 de Julho de 2018.

PADILHA, J. D. et al. Análise da utilização de três diferentes coagulantes na remoção da turbidez de água de manancial de abastecimento. In: Encontro Internacional de Produção Científica, 7. 2011. Maringá. Disponível em:http://www.cesumar.br/prppge/pesquisa/epcc2011/a nais/diana_janice_padilha2.pdf. Acesso em 27 de Junho de 2018.

PERUCCI, C. J.; RODRIGUES, S. G. C.; SILVA, E. P. Aplicação de peróxido de hidrogênio em substituição ao cloro na etapa de pré-oxidação no processo de tratamento de águas de abastecimento como alternativa para a redução da formação de trihalometanos. In: ABES/AESABESP, XXVII Congresso Interamericano de Engenharia Sanitária e Ambiental, FENASAN 2017. Anais eletrônicos. Disponível em :https://www.tratamentodeagua.com.br/wpcontent/uploads/2017/12/I-266.pdf . Acesso em $27 \mathrm{de}$ Junho de 2018.

PIRES, VIVIANE DAS GRAÇAS RODRIGUES. Avaliação da pré-oxidação e da clarificação em escala de bancada na remoção de arsênio e manganês em águas de abastecimento. / Viviane das Graças Rodrigues Pires. $2013.94 \mathrm{f}$.

potabilidade. Diário Oficial [da] União, 12 dez. 2011. Availableat:http://bvsms.saude.gov.br/bvs/saudelegis/g m/2011/prt2914_12_12_2011.html. Acesso em 20 de Maio de 2018.

SOUZA, J. B.; DANIEL, L. A., Comparação entre hipoclorito de sódio e ácido peracético na inativação de E. Coli, Colifagos e $C$. Perfringens em água com elevada concentração de matéria orgânica, Engenharia sanitária e ambiental;10(2):111-7, Jun. 2005. Ilus, tab.

VENEU, D. M.; SILVA, M. P. M.; SALVIO, A. M. D.; DELPHINO, I. A. Z. Tratamento de água eutrofizada através dos processos de pré-oxidação, coagulação e floculação. ENGEVISTA, V. 17, n. 2, p. 175-186, Junho 2015.

VON SPERLING M. Introdução à qualidade das águas e ao tratamento de esgotos. - 3 ed. - Belo Horizonte: Departamento de Engenharia sanitária e Ambiental; Universidade Federal de Minas Gerais. 2005. 